\title{
Erratum to: Adaptive Resource Allocation Algorithms for Multi-user MIMO-OFDM Systems
}

\author{
Najib A. Odhah • Emad S. Hassan • Mohamad Abd-Elnaby • \\ Waleed E. Al-Hanafy • Moawad I. Dessouky • \\ Saleh A. Alshebeili • Fathi E. Abd El-Samie
}

Published online: 7 October 2014

C) Springer Science+Business Media New York 2014

\section{Erratum to: Wireless Pers Commun DOI 10.1007/s11277-014-1994-6}

There was a spelling error in the third author's name in the original publication. It is correct in this erratum.

The online version of the original article can be found under doi:10.1007/s11277-014-1994-6.

\footnotetext{
N. A. Odhah

Department of Electronics Engineering, Faculty of Engineering, and Architecture,

Ibb University, Ibb, Yemen

e-mail: najib_odhah@yahoo.com
}

E. S. Hassan · M. Abd-Elnaby · W. E. Al-Hanafy · M. I. Dessouky · F. E. Abd El-Samie ( $\varangle)$

Faculty of Electronic Engineering, Menoufia University, Menouf 32952, Egypt

e-mail: fathi_sayed@yahoo.com

\section{E. S. Hassan}

e-mail: eng_emadash@yahoo.com

M. Abd-Elnaby

e-mail: moh_naby@yahoo.com

W. E. Al-Hanafy

e-mail: waleed_alhanafy@yahoo.com

M. I. Dessouky

e-mail: dr_moawad@yahoo.com

\section{E. S. Hassan}

Department of Electrical Engineering, Jazan University, Jazan, Saudi Arabia

\section{W. E. Al-Hanafy}

Department of Electrical Engineering, Faculty of Engineering, Albaha University, Al Bahah, Saudi Arabia 
S. A. Alshebeili

Electrical Engineering Department, KACST-TIC in Radio Frequency and Photonics for the e-Society (RFTONICS), King Saud University, Riyadh, Saudi Arabia

email: dsaleh@ksu.edu.sa

F. E. Abd El-Samie

KACST-TIC in Radio Frequency and Photonics for the e-Society (RFTONICS), King Saud University, Riyadh, Saudi Arabia 